\title{
Research on Strategy of Management and Development for Government Micro Blog
}

\author{
Zhe $\mathrm{Li}^{1, \mathrm{a}}$, Yuqiang Yang ${ }^{2, \mathrm{~b}}$, Houhua Shen ${ }^{3, \mathrm{c}}$ \\ ${ }^{1}$ College of International Exchange, Bohai University, Jinzhou, 121013, China \\ ${ }^{2}$ College of Information Science and Technology, Bohai University, Jinzhou, 121013, China \\ ${ }^{3}$ College of Engineering, Bohai University, Jinzhou, 121013, China \\ a503412508@qq.com, byyq8369@163.com, 'shenhouhuashh@126.com
}

Keywords: government affairs; micro blog; management strategy; development strategy; operation mechanism

\begin{abstract}
Government micro blog is an important platform to release information, understand public opinion, pool their wisdom and communicate with the people for government. For the problems existed in the government micro blog management, it clarifies the study meaning, mainly included two aspects. First, improve government micro blog operation mechanisms, including the media guide mechanism, information dissemination mechanism, two-way communication mechanism, daily operation mechanism and evaluate feedback mechanisms; Second, the government micro blog management development strategy, including unified government micro blog information browsing platform, accurately grasped the responsibilities positioning of government micro blog, mastered government micro blog maintenance tips, improved government micro blog reaction speed, paid attention to micro blog from opinion leaders, actively taped the potential interactive objects, strengthen the publicity and promotion of government micro blog and improved the guide ability to online public opinion.
\end{abstract}

\section{Introduction}

In the complicated issue of social management, strengthen and innovate Internet social management is an important content. Micro blog as a new online media, depend on the unique advantages for information dissemination, such as instantaneity, convenience and so on, to be information sources and opinion field that update is the most active on the Internet. As the most cutting-edge network public information dissemination platform and public positions, the government saw the potential political power from micro blog platform, "government micro blog" came into being [1]. Government micro blog refers to official government agencies and officials in the major micro blog platform offered mainly used to understand the aspirations and needs of the masses, grasp the dynamics of public opinion, to resolve network media crisis and promote open government information, using online media platform to help resolve people practical problems, digestion officials and the public misunderstanding, enhancing the interaction between officials and the public, is a special micro-blog with government property. Official government agencies micro blog through real-name authentication on the micro blog platform, it has a public and authoritative, is another new government tools following government portal for the government to open up e-government platform, to enhance the government's public service, and innovate social management.

Government micro blog is an important platform to release information, understand public opinion, pool their wisdom and communicate with the people for government. Currently China is undergoing a special period of economic transformation and social transition, facing intense social change, which presents new challenges for the Chinese administrative reform. The Chinese government is gradually from a single management model complete transition to a service-oriented government. In the process of social transformation, political management functions gradually weakened, social management functions continued to highlight, facing to this change, the traditional social management appeared to be inadequate. Liaoning as the largest economy province and the 
old industrial bases, transformation of government functions and ways of working behind the other developed regions, there are more social conflicts and livelihood issues need to be solved, a new social management is urgent need.

\section{Significances of Carrying Out Research}

The born of government micro blog, has a inherent spreading advantages from the new media, at the same time lead to large-scale media reform, but also reform the government's political participation. Recently, news event caused by the micro-blog, fermentation after micro-blog, released through the micro blog, repeatedly raised strong concern of the community. More and more government agencies initiatively accept the new means of communication, in the form of opening the official micro blog to open government, directly facing public access to information needs, in the growing number of public events to play the agenda-setting, fast communication, social mobilization and other social functions, changing political participation. Government micro blog bring fresh energy, new things and new means of communication provide more way of understanding the government and communicating with the government for the public; at the same time, provide the government communication and government politics with a new platform. This platform is both opportunities and challenges for the government spread, government micro-Bo is a major innovation in traditional government processes, the national government is pushed to the forefront of public opinion and public opinion, government micro-Bo is a new product development of micro era, the Chinese government The functions of the department how to avoid simplistic political operation, how to prevent and control the micro blog politics and the various risks and how to effectively deal with network media network with some unexpected events, these online political issues need to further study and discuss.

Government micro blog as a new social management model, while having a positive role in social management, but for the most current Chinese government, and it did not achieve its proper value. Some government micro blog development philosophy is to build government online government platform, the platform although taking shape, but different members of enthusiasm, the team did not show the effect, the effect is not obvious; though some government micro blog want to narrow the masses distance, but always didactic way, stereotypical thinking remains to improve the dialogue when the dialogue; some government micro blog government information release only as a platform to publish only information, but do not interact with the people, so that government micro Bo became the second open government information network. Government micro blog solve the problems behind the rapid rise, how to make good use of this new micro blog media, to enhance the image of the service-oriented government and promote the further development of China's democratic politics, which is assigned to research the Internet age, but also the research paper focus. This article aims to generalize current development of government micro-Bo, to explore the development of the existing problems, to explore the government micro blog development countermeasures in Liaoning Province to help the government use micro blog platform, with public participation in the public affairs of concern the influence of its powerful synergies to maximize the formation of the new direction of government work, to be closer to people's livelihood and social services provide a useful reference.

\section{Improve the Operation Mechanism of Government Micro Blog}

Operating mechanism refers to in the regular exercise on human society, factors structure, function, and their relationship, the process that these factors play a role and produce influence, working principle and its operational mode affecting this movement. It is to guide and restrict the activities of the relevant decision and with the human, financial, material and other basic norms and corresponding system is to determine the behavior of internal and external factors and the general term mutual relations. Various factors interrelated, interaction, social objectives and tasks to ensure the work truly, must establish a coordinated, flexible and efficient operation mechanism. Sound government micro blog operation mechanism is mainly from the following aspects [2-5]: 
(1) The media guide mechanism. Public events are the fuse generated by public opinion. After the public event occurred, the public hoping fully understand the event information and the latest developments. Once appear the information blind spots, they will speculate on the incident, and then produce a variety of adverse public opinion, and even slanderous rumors spread quickly can lead to even greater crisis. Micro blog with its unique features is rapidly becoming the leading force in the field of public opinion, and government micro blog as the authoritative representative of the public opinion to guide plays an irreplaceable role. If the government micro blog timely opinion toward the right direction, and timely disclosure of information and the latest developments in the real event, can effectively suppress the generation and propagation of rumors, meanwhile promoting the effective governance for event.

(2) Information dissemination mechanism. Government micro blog is the transformation of government functions and reform of the administrative system and the results of innovation and social management. Learn From the spread, the government spread the use of the mass media is the government conducted information dissemination activities, government micro blog is such a propagation behavior. Nature micro blog information dissemination mechanism is to the introduction of social relations people to information dissemination, social relations become an important factor affecting effectiveness of information dissemination. Government micro blog government changed the traditional propagation mechanisms and communication management. Due to the current government micro blog dissemination mechanisms exist many missing, the need for in-depth analysis in terms of dissemination of the body, dissemination of content, media, communication and dissemination of results and other audiences.

(3) Two-way communication mechanism. Two-way communication refers to the presence of communication activities and interactive feedback mechanisms. In the two-way communication process, pass by mutual exchange and share information and maintain a relationship of mutual influence and interaction. Government micro blog appeared to create a new situation "micro blog control" of the government; it has become a political people most convenient channel of communication. With micro blog politics unfolds, increasingly strong awareness of the rights of citizens, for feedback, monitoring the government's increasingly high enthusiasm, sense of responsibility at the same time the government has become more mature, this is the inevitable result of the development of the times. Two-way communication with a positive freedom of speech to protect the public, achieve micro blog matrix of public opinion to guide and promote the image of the government's self-improvement and so on.

(4) The daily operation mechanism. Chinese government introduced for all levels of government agencies and departments, "use the party and government agencies and officials micro blog platform Guide," intensively for government to regulate the use of micro blog. Because of the complexity and diversity of government information sources daily operations of the various departments, improve the mechanism for the daily operations of government micro-Bo also start from the perfect micro blog workforce. Government micro blog does not be managed simply by the staff of government departments, should establish a dedicated management team, clearly defined terms of reference, and specialized staff training in the basics of journalism and communication, with a more specialized workforce management micro blog. Ensure that the relevant functional departments to actively cooperate with government micro blog construction.

(5) Assessment feedback mechanism. Establish evaluation mechanism for government micro blog in information dissemination, public opinion guidance, social management services, and other aspects of government oversight and public reflect and other social effects assessed; establishing feedback mechanisms, timely micro blog publish and manage the problems in the process of feedback to the relevant departments, and promptly correct problems of government micro-Bo, adjust and improve function. At the same time, all aspects of the government micro blog during operation must be the introduction of performance accountability mechanisms to ensure the effective implementation of the system. Government micro blog to interact with the public at the time, if there is arrogance, passive, perfunctory responses, etc., relevant government departments to 
make timely punishment for ignoring complaints and do not actively handling complaints department or staff make a serious deal.

\section{Strategy of Management and Development for Government Micro Blog}

China's social transition, emerging out of the various social contradictions and problems, especially in today's new media, micro blog media environment is to our government daily administrative and social management challenges. If the government can advance with the times, keep pace with the development of micro-Bo, will help to improve our government's ability to govern, improve our public administration, contribute to the solution of social problems. The current situation in our province government micro blog development and problems, the development of measures government micro blog management [6-11]:

(1) Unified government micro blog information browsing platform. To make multiple government micro blog platform work together to provide government services, it is recommended by a third party of the existing government micro blog resource integration, the establishment of a comprehensive government micro blog navigation platform, set on different government micro blog platform opened tweets for users to provide a collection of government information. Comprehensive government micro blog navigation platform to address the physical separation between the various government micro blog, micro blog platform will be information from multiple collections on the same page, saving the log on to multiple micro blog platform browser government information process. Internet users just log government micro blog site navigation, you can browse all the information on each platform; managers just log government micro blog site navigation, you can see the other government micro blog published information, it is conducive to the coordination process, and facilitate government micro blog technology and management experience exchange operations.

(2) Accurately grasped the responsibilities positioning of government micro blog. Government open micro blog departments should be based on functional and operational scope, accurately grasp the role of the role of government micro blog positioning, the use of the advanced tools and management tools, promote, improve, adjust and sort of work processes, improve management and service capabilities, micro blog user submitted in response to a variety of demands, according to the business scope of timely disclosure of all government information, should not blindly follow the trend. Although the spread of the micro blog information quickly, but the status of micro-Bo can not completely replace newspapers, television and radio and other traditional information dissemination platform, only the government micro blog and other platforms combined, in order to achieve better results. At the same time, distinguish the boundaries between official and personal micro blog. Officials opened personal micro blog, micro blog belonging to the ordinary citizen, does not mean that the views of the government, in order to prevent inappropriate personal remarks misleading users of the government.

(3) Mastered government micro blog maintenance tips. The main government micro blog party and government bodies, and general personal micro blog body is different, involving the majority of the content is also relevant work of government departments, representatives of the government image. The accuracy of the information released by government micro blog requirements, maintenance personnel should always pay attention to the accuracy of information published. There is a lot of information on the micro blog, and updated information quickly, the audience for each reading time and is very short. This requires attention to the time of writing the contents of the text Introduction to refining. Government micro blog is to serve the people and the establishment, release of information to the masses. When the information is released to the readability, the appropriate use of the network and colloquial language, the initiative closer relationship with the people, build a good atmosphere discourse. Diversification of communication, not just text messages, and multimedia presentations can be illustrated with FIG should match Bowen phase.

(4) Improve government micro blog reaction speed. The most important feature of micro blog is fast. In the era of traditional media, presentation and dissemination of news measured in days. On the Internet age, presentation and dissemination of news measured in hours. And into the era of 
micro blog, the presentation and dissemination of news cycles shortened again, is in seconds. Especially after the incident or crisis occurs, the government must respond quickly, the first time the use of micro-Bo authoritative information, clarification and report events progress, guide the trend of changes in the network of public opinion. Internet users respond promptly is an important responsibility for the kind of respect public opinion, but also the commitment of the government. Otherwise, it will be full of the Internet gossip and rumors, serious and even lead to large-scale mass incidents. However, it does not mean they should immediately respond quickly to events qualitative conclusion, the need to hold a cautious attitude and avoid indiscretion to the public cause visual confusion.

(5) Paid attention to micro blog from opinion leaders. All users on the network does not rank, status and wealth differences, all users are equal. Some users are real names, some users are nicknames anonymity. Whether real name or nickname, behind corresponds to a real person, every post is a real portrayal of the soul. On freedom, equality and open network, in order to become a particular area, the industry's opinion leaders, need to go through a long period of posting, replies, participate in discussions and more than the number of posts and high quality in order to be accepted by the network users. Most opinion leaders are experts in the field; it has a higher prestige and visibility. Government micro blog pay more attention to the industry's opinion leaders, multi forwarded their posts, communicate and collaborate with them, let them within the scope of its own fans government micro blog, micro blog to expand the government's influence.

(6) Actively taped the potential interactive objects. As a new way of governance and administration of the network, the government micro blog should play a proactive communication skill, not merely passively receive questions or help information raised by user. For long-term crowd of loyal fans, or have considerable influence on the fans, such as stars, public intellectuals, the media and other micro blog account data mining, interactive object seek potential exchange topic, a representative of users to understand the interests of the demands, wishes and ideas. As official micro blog government agencies, is perfectly placed to achieve the collection micro blog database, sorting and processing, certain establishments or departments or units with higher authorities sharing of resources, to tap the huge potential more interactive objects, expand government micro blog public policy dissemination process user's participate depth.

(7) Strengthen the publicity and promotion of government micro blog. The good promotion work of government micro blog and enhance the influence of government micro-Bo is directly related government micro blog service effectiveness. Effective promotional activities mainly from the following three aspects: First, do the promotion on the line early, so that the people understand the purpose of existence and the opening of government micro-Bo, welcome the attention and supervision by the masses. With the influential traditional media, propaganda work; second is to pay attention to the daily operations of the organization online and offline creative activities, combined with the focus of its own functional orientation and service objects on the micro blog organize creative activities initiated or hot topics, expand the influence of government micro-Bo, improve service levels; Third, the integration of local government micro blog realize cluster development. By integrating micro blog resources within the region, so that government micro blog concerted efforts to enhance the scope and influence of radiation.

(8) Improved the guide ability to online public opinion. Micro blog has become an important public places, after the news media reported that the focus of Chinese public opinion quickly transferred to micro blog users broke the news media of choice more towards micro blog. Faced with such a situation, government micro blog is imperative to guide online public opinion, public opinion if the network is not to be guided in a timely manner, can easily cause imbalance micro blog public opinion environment, causing negative effects, but will have a negative social stability and harmony influences. Specific measures include: the establishment of multi-sect oral linkage mechanism, a network of public opinion to guide force; innovative ideas, to grasp the characteristics and laws of the formation of a network of public opinion; with traditional media and new media interaction and cooperation, correctly guide public opinion; focus on the culture of solidarity and 
opinion leaders, guide the direction of public opinion; when major emergencies occur, the effective release of authoritative information.

\section{Conclusion}

Micro blog as a new network communication tool for people to create a huge public space for discussion, and gradually into public affairs, access to comprehensive and timely information through the micro blog, tracking the progress of major public events, actively express their opinions, express interest demands, participate in government decision-making, and ultimately affect the country's political and government decision-making. Government agencies and public officials have gradually seen micro blog outstanding contributions to government information and social management, and actively open micro blog, the role of government micro-Bo in the public policy process of communication has become increasingly prominent. Government micro blog development strategy developed in this paper help governments use micro blog platform, and strive to do the work of guiding public opinion, through the micro blog asked the government to the people, ask need to the people, ask measure to the people and properly respond to public hot spots, help promote social harmony and stability, conducive to better serve the party and state work, services for the masses, so that the government micro blog can be sustained and healthy development, and play its powerful features of "micro blog politics".

\section{Acknowledgement}

This work is supported by social science fund project of Liaoning province (L13BGL013): Research on management practice and development strategy of government microblogging in Liaoning province.

\section{References}

[1] X. Q. Zhang, "Research on the problems and countermeasures of local government micro blog operation in China," Master's degree of Shaanxi Normal University, 2014.

[2] D. X. Cui, "The Analysis Of The Government Micro-blog On The Basis Of Theory In Public Sphere," Master's degree of Donghua University, 2012.

[3] Z. M. Liang, "On the communication mechanism of government micro blog," Journalism Lover, vol. 27, no. 24, pp. 35-36, 2012.

[4] T. T. Mao, Y. P. Chen, "Research on the construction of public opinion guiding mechanism of government micro blog," E-Government, vol. 11, no. 3, pp. 62-6, 2014.

[5] X. Q. He, "Study on structuring the two-way communication mechanism of the government micro blog in emergency," Master's degree of Jiangxi Normal University, 2014.

[6] Y. Li, "Thinking on the development of government micro blog," Journal of Jiangxi Administration Institute, vol. 16, no. 1, pp. 13-15, 2014.

[7] W. Q. Chen, X. N. Li, "The influence of government micro blog on Chinese government management and the countermeasures," E-Government, vol. 12, no. 4, pp. 38-47, 2014.

[8] Z. H. Xiong, "Research on the communication of government micro blog in China," Master's degree of Nanchang University, 2012.

[9] X. Mao, "Study on confronting problems in the development of government affairs microblog and corresponding countermeasures," Master's degree of Southwestern University, 2014.

[10] W. W. Zhang, " Henan Government Micro-blog Research: Based on the Communication Perspective of Public Policy," Master's degree of Henan University, 2014.

[11] P. Q. Chen, "The status quo, problems and countermeasures of the development of government micro blog in China," Journal of Pu'er University, vol. 31, no. 1, pp. 21-23, 2015. 